\title{
Mass-analysed Ion Kinetic Energy and Collisionally Induced Dissociation Mass Spectra of Clusters of Acetylated Xylo-oligosaccharides with Protonated Ammonia and Methylamine
}

\author{
V. Kováčik and J. Hirsch \\ Institute of Chemistry, Slovak Academy of Sciences, Dúbravská cesta, 84238 Bratislava, Czechoslovakia \\ P. Kováč \\ NIDDK, National Institutes of Health. Bethesda, Maryland 20892, USA
}

H.-Fr. Grützmacher

Faculty of Chemistry, University of Bielefeld, Universitätstrasse, D-4800 Bielefeld, Germany

\begin{abstract}
Per- $O$-acetylated methyl glycosides of D-xylan-type di- and trisaccharides were studied by mass-analysed ion kinetic energy (MIKE) and collisionally induced dissociation (CID) mass spectrometry using protonated ammonia and methylamine, respectively, as reaction gases in chemical ionization (CI). The oligosaccharides form abundant cluster ions, $\left|\mathrm{M}+\mathrm{NH}_{4}\right|^{+}$or $\left|\mathrm{M}+\mathrm{CH}_{3} \mathrm{NH}_{3}\right|^{+}$, and the main fragmentation of these ions in the MIKE and CID spectra is the cleavage of interglycosidic linkages. Thus, $\mathrm{CI}\left(\mathrm{NH}_{3}\right)$ or $\mathrm{CI}\left(\mathrm{CH}_{3} \mathrm{NH}_{2}\right)$ spectra in combination with the MIKE or CID spectra allow the molecular masses, the masses of monosaccharide units and the branching point in oligosaccharides to be established. In the case of disaccharides, it is possible to distinguish the $(1 \rightarrow 2)$ linkage from the other types of linkages.
\end{abstract}

\section{INTRODUCTION}

D-Xylans and (4-O-methyl-D-glucurono)xylans are components of industrially important woods and other plants. ${ }^{1}$ With the aim of using mass spectrometric methods for the structure elucidation of oligosaccharides related to $\mathrm{D}$-xylans, we and others have made systematic studies of per- $O$-methylated oligosaccharides. ${ }^{2.3}$ The sequential analysis of oligosaccharides by electron impact (EI) mass spectrometry has also been described. ${ }^{4}$ Other important results in this regard have been achieved by the fast atom bombardment (FAB) mass spectrometry of underivatized methyl glycosides with subsequent analysis of the $[\mathrm{M}+\text { glycerol }+\mathrm{H}]^{+}$ cluster ions by mass analysed ion kinetic energy (MIKE) and collisionally induced dissociation (CID) mass spectrometry. ${ }^{5}$ In continuation of our studies directed at the mass spectrometric analysis of xylooligosaccharides, we examined the gas-phase reactions of per-O-methylated $\mathrm{D}$-xylotriose with several protonated reagents by chemical ionization (CI) mass spectrometry. ${ }^{\circ}$ The ammonium ions produced from ammonia and methylamine yicld abundant cluster ions under these conditions with the per- $O$-methylated oligosaccharides studied. In this contribution, the results of an investigation of the per- $O$-acetylated methyl glycosides of D-xylan-type oligosaccharides (1-10) by $\mathrm{CI}$, using ammonia or methylamine as reaction gas, are discussed. MIKE and CID mass spectrometry were used to study the fragmentation of these cluster ions.

$$
\begin{aligned}
1 & =\alpha \text {-D-Xylp- }(1 \rightarrow 2)-\beta \text {-D-Xylp } \\
2 & =\beta \text {-D-Xylp- }(1 \rightarrow 2)-\beta \text {-D-Xylp } \\
3 & =\alpha \text {-D-Xylp- }(1 \rightarrow 3)-\beta \text {-D-Xylp } \\
4 & =\beta \text {-D-Xylp- }(1 \rightarrow 3)-\beta \text {-D-Xylp } \\
5 & =\alpha \text {-D-Xylp- }(1 \rightarrow 4)-\beta \text {-D-Xylp } \\
\mathbf{6} & =\beta \text {-D-Xylp- }(1 \rightarrow 4)-\beta \text {-D-Xylp } \\
7 & =\beta \text {-D-Xylp- }(1 \rightarrow 2)-\beta \text {-D-Xylp- }(1 \rightarrow 4)-\beta \text {-D-Xylp } \\
\mathbf{8} & =\beta \text {-D-Xylp- }(1 \rightarrow 3)-\beta \text {-D-Xylp- }(1 \rightarrow 4)-\beta \text {-D-Xylp } \\
9 & =\beta \text {-D-Xylp- }(1 \rightarrow 4)-\beta \text {-D-Xylp- }(1 \rightarrow 4)-\beta \text {-D-Xylp } \\
10 & =\beta \text {-D-Xylp- }(1 \rightarrow 4)-\beta-\mathrm{D}-X y l p-(2 \leftarrow 1)-\beta \text {-D-Xylp }
\end{aligned}
$$

\section{EXPERIMENTAL}

The synthesis of the methyl glycosides of oligosaccharides 1-10 has been described previously ${ }^{7 \ldots 11}$ and the methyl glycosides were per- $\mathrm{O}$-acetylated by conventional techniques using acetic anhydride-pyridine.

The Cl mass spectra were obtained with a VG $\mathrm{ZAB}-2 \mathrm{~F}$ mass spectrometer using the direct inlet system for the sample, $70 \mathrm{eV}$ energy and an ion source temperature of $\sim 180^{\circ} \mathrm{C}$. Ammonia or methylamine was introduced into the ion source as reaction gas until the pressure reading at the ion source gauge was $10^{-5}$ 
$10^{-6}$ mbar $\left(1\right.$ bar $=10^{5} \mathrm{~Pa}$ ). In the case of disaccharides 1-6 deuterated ammonia was also used as a reaction gas. To obtain the MIKE and CID spectra, the ions under study were focused magnetically into the second field-free region (2nd FFR) between the magnet and the electrostatic analyser, and the spectra were recorded by scanning the deflection voltage of the electrostatic analyser. To perform CID in the collision cell of the 2nd FFR, helium was introduced until the main ion beam was attenuated by $\sim 50 \%$.

\section{RESULTS AND DISCUSSION}

The $\mathrm{CI}\left(\mathrm{NH}_{3}\right)$ spectra and $\mathrm{CI}\left(\mathrm{CH}_{3} \mathrm{NH}_{2}\right)$ spectra of 1-10 exhibit abundant cluster ions $\left[\mathrm{M}+\mathrm{NH}_{4}\right]^{+}$and $\left[\mathrm{M}+\mathrm{CH}_{3} \mathrm{NH}_{3}\right]^{+}$, respectively, as in the case of the per- $O$-methylated sugars. ${ }^{6}$ In particular, the peak of the cluster ions $\left[\mathrm{M}+\mathrm{CH}_{3} \mathrm{NH}_{3}\right]^{+}$is dominant in the spectrum, permitting an easy determination of the relative molecular masses of the per- $O$-acetylated methyl glycosides of the oligosaccharides. However, no fragmentation of these ions is observed in their MIKE spectra. The MIKE spectra of $\left[\mathrm{M}+\mathrm{NH}_{4}\right]^{+}$adduct ions of per- $O$-acetylated disaccharides $1-6$ are presented in Table 1. The only fragmentation process observed is the cleavage of glycosidic linkages, as shown in Scheme 1. Interestingly, in the case of a $(1 \rightarrow 2)$ linkage the cleavage of this interglycosidic bond takes place much easier than in the case of $(1 \rightarrow 3)$ and $(1 \rightarrow 4)$ linkages [see the much smaller intensity ratio baA $\mathrm{A}_{1} / \mathrm{aA}_{1}(\mathrm{~m} / z$ 475/259) for 1 and 2].

More extensive fragmentation is observed in the CID spectra of both types of cluster ions of 1-6 shown in Tables 2 and 3. As in the case of the MIKE spectra, a cleavage of adduct ions $\left[\mathrm{M}+\mathrm{NH}_{4}\right]^{+}$(Table 2) gives rise to the ions $\left[\mathrm{M}-{ }^{\circ} \mathrm{OCH}_{3}\right]^{+}\left(\mathrm{baA}_{1}, m / z 475\right)$ and ions $\mathrm{aA}_{1}(m / z 259)$, representing the non-reducing unit of the disaccharide. Again the cleavage of a $(1 \rightarrow 2)$ interglycosidic linkage occurs with special ease, as indicated by small baA $A_{1} / \mathrm{aA}_{1}$ intensity ratio $(m / z 475 / 259)$ for 1 and 2. Further fragmentations of these ions proceed by elimination of $\mathrm{CH}_{3} \mathrm{COOH}, \mathrm{CH}_{2} \mathrm{CO}$ and $\mathrm{CO}$ molecules as usual, giving rise to the ions $\mathrm{A}_{2}$ at $\mathrm{m} / z$ 199, $\mathrm{A}_{3}$ at $m / z 157$ and $139, \mathrm{~A}_{4}$ at $m / z 97$ and $\mathrm{CH}_{3} \mathrm{CO}^{+}$

Table 1. MIKE mass spectra of $\left|\mathrm{M}+\mathrm{NH}_{4}\right|^{+}$ions $(m / z$ 524) of disaccharide derivatives $1-6$

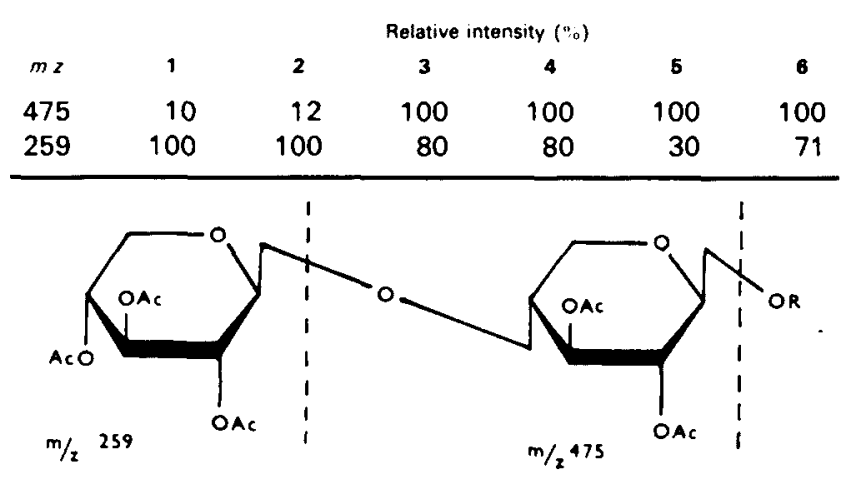

Scheme 1
Table 2. CID mass spectra of $\left|\mathrm{M}+\mathrm{NH}_{4}\right|^{+}$ions $(m / z 524)$ of disaccharide derivatives 1-6

\begin{tabular}{rrrrrrr}
$m z$ & \multicolumn{7}{c}{ Relative intensity $(\%)$} \\
475 & 1 & \multicolumn{1}{c}{2} & 3 & \multicolumn{1}{c}{4} & \multicolumn{1}{c}{5} & \multicolumn{1}{c}{6} \\
259 & 100 & 100 & 100 & 100 & 100 & 100 \\
229 & 10 & 12 & 10 & 9 & 8 & 7 \\
199 & 52 & 61 & 61 & 50 & 83 & 57 \\
169 & 12 & 12 & 8 & 8 & 8 & 5 \\
157 & 75 & 71 & 61 & 50 & 75 & 75 \\
139 & 50 & 71 & 43 & 50 & 60 & 45 \\
109 & 4 & 4 & 4 & 4 & 4 & 4 \\
97 & 68 & 71 & 51 & 40 & 44 & 31 \\
43 & 60 & 51 & 26 & 30 & 28 & 25 \\
\hline
\end{tabular}

at $m / z 43$. The peaks of the other series of ions at $m / z$ 229,169 and 109 are less intense. These fragmentation routes were confirmed by measuring the MIKE and CID spectra of $\left[\mathrm{M}+\mathrm{ND}_{4}\right]^{+}$adduct ions in the $\mathrm{CI}$ $\left(\mathrm{ND}_{3}\right)$ spectra of 1-6. Only the masses of the cluster ions have been shifted by $4 \mathrm{u}$ to higher values.

The CID spectra of the cluster ion $\left[\mathrm{M}+\mathrm{CH}_{3} \mathrm{NH}_{3}\right]^{+}$ (Tablc 3) again show distinct signals of fragments baA and a $A_{1}$ at $m / z 475$ and 259 due to the cleavages of glycosidic bonds of $1-6$. However, the intensity ratios do not correlate with the type of glycosidic bonds. Furthermore, the degradation of these ions by losses of $\mathrm{CH}_{3} \mathrm{COOH}$ and $\mathrm{CH}_{2} \mathrm{CO}$ is more intense, compared with the CID spectra of the corresponding $\left[\mathrm{M}+\mathrm{NH}_{4}\right]^{+}$cluster ions, and ions arising from the fragmentation of the pyranoid rings (e.g. at $m / z 245$, $229,169,127$ and 109) are more pronounced. Finally, a large portion of the fragment ion current is carried away by $\mathrm{CH}_{3} \mathrm{NH}_{3}{ }^{+}$ions $(m / z 32)$, characteristic of the reactant gas used.

The information obtained from the $\mathrm{CI}\left(\mathrm{NH}_{3}\right)$ or $\mathrm{CI}\left(\mathrm{CH}_{3} \mathrm{NH}_{2}\right)$ spectra and from the MIKE or CID spectra of the cluster ions $\left[\mathrm{M}+\mathrm{NH}_{4}\right]^{+}$and $[\mathrm{M}$ $\left.+\mathrm{CH}_{3} \mathrm{NH}_{3}\right]^{+}$, respectively, can easily be used for the structure elucidation of the per- $O$-acetylated methyl glycosides of disaccharides. The determination of relative molecular mass is unambiguously possible from the

Table 3. CID mass spectra of $\left.\mid \mathrm{M}+\mathrm{CH}_{3} \mathrm{NH}_{3}\right]^{+}$adducts $(m / z$ 538) of disaccharide derivatives $\mathrm{I}-6$

\begin{tabular}{rrrrrrr}
$m: z$ & \multicolumn{7}{c}{ Relative intensity $(\%)$} \\
475 & 1 & 2 & 3 & 4 & 5 & 6 \\
415 & 6 & 31 & 19 & 18 & 55 & 53 \\
259 & 9 & 50 & 30 & 25 & 33 & 36 \\
245 & 30 & 63 & 52 & 56 & 88 & 100 \\
229 & 15 & 31 & 15 & 22 & 48 & 45 \\
199 & 13 & 13 & 28 & 16 & 33 & 57 \\
169 & 26 & 52 & 59 & 50 & 48 & 45 \\
157 & 39 & 57 & 30 & 26 & 22 & 30 \\
139 & 93 & 76 & 94 & 87 & 93 & 98 \\
127 & 71 & 87 & 94 & 90 & 96 & 84 \\
109 & 15 & 21 & 15 & 18 & 15 & 10 \\
97 & 19 & 13 & 10 & 10 & 15 & 20 \\
43 & 85 & 100 & 100 & 100 & 100 & 77 \\
32 & 278 & 210 & 220 & 215 & 220 & 165 \\
\hline
\end{tabular}


masses of the respective cluster ions. The determination of the masses of monosaccharide units uses the large peaks in the MIKE and CID spectra of the cluster ions $\left[\mathrm{M}+\mathrm{NH}_{4}\right]^{+}$, and it is also possible to differentiate a $(1 \rightarrow 2)$ interglycosidic linkage from the other types of glycosidic junctions. However, it is not possible to distinguish between $\alpha$ - and $\beta$-anomers. Better information can be obtained only by the method of determining interglycosidic linkages in disaccharides using fast atom bombardment high-performance tandem mass spectrometry and high-energy CID measurements of $A_{1}$ $C$ (1) carbenium ions derived from trideuteroacetylated dihexopyranosides. ${ }^{2}$

The per- $O$-acetylated trisaccharides $\mathbf{7 - 1 0}$ also give rise to abundant cluster ions $\left[\mathrm{M}+\mathrm{NH}_{4}\right]^{+}$and $\left[\mathrm{M}+\mathrm{CH}_{3} \mathrm{NH}_{3}\right]^{+}$in their $\mathrm{CI}\left(\mathrm{NH}_{3}\right)$ and $\mathrm{CI}\left(\mathrm{CH}_{3} \mathrm{NH}_{2}\right)$ spectra, respectively. The $\left[\mathrm{M}+\mathrm{CH}_{3} \mathrm{NH}_{3}\right]^{+}$cluster ions are again very stable and do not give MIKE spectra. The MIKE spectra of the $\left[\mathrm{M}+\mathrm{NH}_{4}\right]^{+}$adduct ions are shown in Table 4, cleavages of the glycosidic bonds again being the only processes observed. Again the cleavage of the $(1 \rightarrow 2)$ interglycosidic linkage of 7 is strongly preferred. A branched trisaccharide de ative (10) can in principle not form ions baA $A_{1}$ at $m / z 475$, so this branching is easily detected.

The CID spectra of the $\left[\mathrm{M}+\mathrm{NH}_{4}\right]^{+}$cluster ions of trisaccharides 7-10 are presented in Table 5. The ions ba $_{1}$ formed by splitting of the glycosidic linkages appear at $m / z 475$ and 259 , and further fragmentation of these ions gives rise to ions $\mathrm{aA}_{2}$ at $m / z 199, \mathrm{aA}_{3}$ at $m / z$ 157 and 139 and $\mathrm{aA}_{4}$ at $m / z$ 97. The CID spectra of the adduct ions $\left[\mathrm{M}+\mathrm{CH}_{3} \mathrm{NH}_{3}\right]^{+}$of the trisaccharides 7-10 are given in Table 6. Similarly to the MIKE spectra of the $\left[\mathrm{M}+\mathrm{NH}_{4}\right]^{+}$adduct ions, the fragmentation occurs predominantly at the interglycosidic linkages. The high-mass range of the spectra exhibits peaks at $m / z 694$ and 634 duc to ions formed by the loss of one or two $\mathrm{CH}_{3} \mathrm{COOH}$ molecules from the adduct ions.

Table 4. MIKE mass spectra of $\left|\mathrm{M}+\mathrm{NH}_{\mathrm{a}}\right|^{+}$ions $(\mathrm{m} / \mathrm{z} \mathbf{7 4 0})$ of trisaccharide derivatives $7-10$

\begin{tabular}{ccccc} 
& \multicolumn{5}{c}{ Relative intensity $(" .)}$. \\
$m z$ & 7 & 8 & 9 & 10 \\
475 & 10 & 100 & 100 & \\
259 & 100 & 66 & 60 & 100 \\
\hline
\end{tabular}

Table 5. CID mass spectra of $\left|\mathrm{M}+\mathrm{NH}_{4}\right|^{+}$ions $(\mathrm{m} / \mathrm{z} 740)$ of trisaccharide derivatives $7-10$

\begin{tabular}{rrrrr}
$m z$ & \multicolumn{5}{c}{ Relative intensity ("..) } \\
475 & \multicolumn{1}{c}{} & $\mathbf{8}$ & $\mathbf{9}$ & 10 \\
259 & 20 & 78 & 38 & \\
199 & 100 & 84 & 100 & 100 \\
157 & 50 & 92 & 53 & 50 \\
139 & 65 & 100 & 57 & 40 \\
97 & 35 & 96 & 63 & 30 \\
43 & 65 & 78 & 37 & 50 \\
\hline
\end{tabular}

Similarly to the $\mathrm{CI}\left(\mathrm{NH}_{3}\right)$ and $\mathrm{CI}\left(\mathrm{CH}_{3} \mathrm{NH}_{2}\right)$ spectra of disaccharides, the spectra of the trisaccharides can be used to determine relative molecular masses. The MIKE and CID spectra of the respective adduct ions, in particular of $\left[\mathrm{M}+\mathrm{NH}_{4}\right]^{+}$, give additional structural information concerning the masses of per- $O$-acetylated monosaccharide units. The absence of the oxonium ions $\mathrm{baA}_{1}$ at $m / z 475$ (and its fragmentation product baA $\mathrm{A}_{2}$ at $m / z 415$ ) containing two monosaccharide units in the MIKE and CID spectra of the cluster ions of 10 confirms the presence of branching in the trisaccharide. Finally, the preferred cleavage of a $(1 \rightarrow 2)$ interglycosidic linkage is also observed in the MIKE and CID spectra of adduct ions of the trisaccharide.

\begin{tabular}{|c|c|c|c|c|}
\hline \multirow[b]{2}{*}{$m z$} & \multicolumn{4}{|c|}{ Relative intensity $\left({ }^{\prime \prime}.\right)$} \\
\hline & 7 & 8 & 9 & 10 \\
\hline 694 & 80 & 78 & 80 & 30 \\
\hline 634 & 90 & 60 & 94 & 45 \\
\hline 475 & 10 & 30 & 9 & \\
\hline 415 & 10 & 31 & 10 & \\
\hline 259 & 100 & 50 & 100 & 81 \\
\hline 245 & 20 & 26 & 44 & \\
\hline 199 & 40 & 74 & 70 & 67 \\
\hline 169 & 10 & 22 & & \\
\hline 157 & 50 & 100 & 80 & 100 \\
\hline 139 & 60 & 85 & 72 & 50 \\
\hline 97 & 60 & 70 & 65 & 80 \\
\hline 43 & 20 & 38 & 60 & 42 \\
\hline 32 & 60 & 72 & 110 & 74 \\
\hline
\end{tabular}

\section{REFERENCES}

1. A. M. Stephen, in The Polysaccharides, ed. by G. O. Aspinall, Vol. 2. p. 98. Toronto. Sydney. Tokyo (1982).

2. J. Comtat, J.-P. Joselau, C. Bosso and F. Barnoud, Carbohydr. Res. 38, 217 (1974).

3. V. Kováčik, V. Mihálov and P. Kovác, Carbohydr. Res. 88, 189 (1981).

4. V. Kovàcik and P. Kovàc, Carbohydr. Res. 105, 251 (1982).

5. V. Kovácik, E. Petráková, J. Hirsch, V. Mihálov, W. Heerma and C. Versluis, Biomed. Environ. Mass Spectrom. 17, 455 (1988).
6. V. Kováčik and H.-Fr. Grützmacher, Org. Mass Spectrom. 25, 687 (1990)

7. J. Hirsch and P. Kovác, Carbohydr. Res. 77, 24 (1979).

8. P. Kovád, Collect. Czech. Chem. Commun. 45, 892 (1980).

9. P. Kovác, Chem. Zvesti 34, 234 (1980).

10. P. Kovác, J. Hirsch and V. Kovácik, Carbohydr. Res. 75, 109 (1979).

11. P. Kovác and J. Hirsch, Carbohydr. Res. 79, 303 (1980)

12. B. Domon, D. R. Müller and W. J. Richter, Int. J. Mass Spectrom. Ion Processes 100, 301 (1990). 